\title{
LIVRO INFANTIL E PROJETO GRÁFICO: UMA RELAÇÃO ENTRE IMAGEM E TEXTO
}

\author{
Patrícia de Sá Maia \\ Universidade Estadual de Londrina \\ patigrafico@gmail.com \\ Profa. Dra. Rosane Fonseca de Freitas Martins \\ Universidade Estadual de Londrina \\ rosaneffm@gmail.com
}

\section{Resumo:}

O mercado editorial brasileiro é promissor especialmente no que diz respeito ao livro infantil, que tem ganhado notoriedade, imagens e projetos gráficos mais elaborados. Neste contexto, este estudo provoca uma reflexão sobre a imagem literária infantil: como é produzida, qual a sua relação com o projeto gráfico, qual é o impacto do projeto gráfico e como a criança se relaciona com o livro; e sobre os caminhos para alcançar o mundo literário infantil. Apresenta um estudo dos processos históricos da literatura infantil, focando na produção imagética e os principais conceitos que nortearam sua evolução. A metodologia emprega pesquisa mista em 3 etapas: delineamento de dados primários e secundários, incluindo a análise de livros de autores brasileiros e estrangeiros; a produção de um livro infantil com linguagem interativa; e a terceira mostra a pesquisa de campo com crianças para a análise da relação com o livro. Os resultados apresentam a importância da integração entre texto, imagem e projeto gráfico e como essa interação pode estimular ou não o leitor. Espera-se contribuir para um maior entendimento do processo de produção da imagem literária no livro infantil, e a relação da criança com essa imagem.

Palavras-chave: literatura infantil, imagem literária, relação imagem/texto, leitura de imagem, projeto gráfico.

\footnotetext{
Abstract:

The Brazilian publishing market is promising especially with regard to children's book, which has gained notoriety, images and more elaborate graphic designs. In this context, this study brings a reflection on childhood literary image: it is produced, what is your relationship with the graphic design, which is the impact of graphic design and how the child relates to the book; and on the ways to reach the children's literary world. It presents a study of historical processes of children's literature, focusing on image production and the main concepts that guided their evolution. The methodology employs joint research in three steps: design of primary and secondary data, including analysis of Brazilian and foreign authors books;
} 
the production of a children's book with interactive language; and the third shows the field of research with children for analysis of the relationship with the book. The results show the importance of the integration of text, image and graphic design and how this interaction can stimulate or not the reader. Expected to contribute to a greater understanding of the production process of the literary image in the children's book, and the child's relationship with this image.

Keywords: children's literature, literary image, interface image / text, image reading, graphic design

\section{INTRODUÇÃO}

Apesar da situação de crise e instabilidade financeira atual, o mercado editorial vem crescendo de maneira consistente no Brasil. De acordo com a Câmara Brasileira do Livro, em 2014 foram editados e produzidos 475.184.837 livros de autores nacionais (FIPE, 2014). E com um mercado crescente, a produção literária aumenta consideravelmente. Se isso por um lado é positivo, por outro pode ser preocupante se essa produção for pensada visando apenas lucro, sem o devido cuidado com o público que irá consumir esse produto, tanto no que se refere ao projeto gráfico quanto em relação ao conteúdo. A descoberta de um mercado infantil que pode consumir literatura, mais até do que o público adulto impulsionou uma produção desenfreada de livros infantis. "A literatura infantil é, muitas vezes, considerada uma literatura de massa, de menor qualidade, produzida em grande escala e pouco elaborada, pois o que o mercado deseja é a venda e o consumo, a quantidade, não a qualidade." (SILVA, 2009, p. 138).

Isso faz com que essa produção seja comparável a produtos feitos em larga escala para grandes mercados, com todas as implicações que isso representa. Entre elas, a alta demanda exige velocidade de produção e baixo custo, resultando em baixa qualidade do material utilizado, incluindo projeto gráfico e até conteúdo dos livros.

Apesar dessa produção mercadológica sem preocupação pedagógica ou literária, o Brasil tem um berço muito forte no que se refere à literatura infantojuvenil, que teve início com Monteiro Lobato, com uma produção literária esmerada do conteúdo à forma, não só por sua preocupação nacionalista, mas pelo respeito e compreensão de seu principal público alvo, o infantil. Sua produção foi extremamente significativa. Esses fatores somados à relação que estabelecera com o público e a educação tornaram-se um verdadeiro divisor de águas na história da literatura brasileira. Para Albino (s.d., p.8): "Autor de uma obra renovadora pelo rompimento com os moldes tradicionais e pela criação de novas expectativas, Lobato tornou-se não apenas marco na literatura infantil brasileira, mas sua referência máxima.".

Com o crescimento do mercado literário e a chegada das novas tecnologias, que tem como base de comunicação a imagem, os textos e as ilustrações se transformaram. Surgiram novas formas de ler, e até mesmo de usar o livro, como os livros-brinquedos, livros-objetos, livros interativos, e-books e áudio-books. Essa mudança da relação com a imagem e sua interação se estendeu ao universo literário, especialmente no âmbito infantil. Os livros para crianças das últimas décadas estão cada vez mais imagéticos e se multiplicam nas prateleiras de livrarias, mercados, lojas 
de conveniência e stands de shoppings.

Diante deste contexto surgem as questões que motivaram o desenvolvimento deste trabalho: que critérios norteiam a produção da imagem literária e do projeto gráfico; o tipo de relação se estabelece entre eles; a influência do mercado nessa produção. E ainda, durante o processo de produção da imagem há uma busca, ou preocupação da interação da criança com esse livro? A imagem literária e o próprio projeto gráfico favorecem essa interação? Essas questões direcionaram o problema que norteia esta pesquisa: Qual a importância da produção sistematizada da imagem literária no projeto gráfico do livro infantil?

Foi produzido um livro de texto literário $1^{1}$ infantil com base na análise da produção de imagem literária pela ótica do design gráfico a fim de fomentar a discussão da função literária da imagem no livro infantil, cujo objetivo foi tratar da relação da criança com o livro físico e a imagem literária e sua interação.

Como metodologia, trata-se de uma pesquisa de natureza exploratória, descritiva e qualitativa, com delineamento de dados primários e secundários, e estratégia baseada na videofotoetnografia. Trata do livro físico e sua composição e uma análise do contato da criança com esse livro para identificar como ela o percebe: a imagem e o texto, as relações e interpretações que faz da narrativa para saber se o livro é compatível com suas necessidades, anseios, compreensão e interesse. Espera-se instigar a discussão sobre a função do design e da produção de imagem no âmbito de contribuição, auxílio e suporte à leitura e fruição do texto literário.

\section{FUNDAMENTAÇÃO TEÓRICA}

\subsection{A imagem literária infantil}

Desde que nasce o homem busca se comunicar, e nesse processo desenvolve a linguagem, que se inicia pelos sentidos. Ainda como embrião é possível sentir e perceber. Ao abrir dos olhos essa percepção do mundo vai se ampliando e com ela a formatação da linguagem. Ao ler as imagens e situações ao seu redor, o bebê principia uma busca de apreensão e compreensão, seguida pelo som e pelo tato: as primeiras sensações físicas que trazem as informações do mundo "recém-chegado". De pronto e ao longo da vida aprenderemos sempre com o "mundo vivido", através de nossa sensibilidade e percepção, que permitem nos alimentarmos das espantosas qualidades do real: sons, cores, sabores, texturas e odores, numa miríade de impressões que o corpo ordena, na construção do sentido primeiro. O mundo antes de ser tomado como matéria inteligível, surge a nós como objeto sensível. (DUARTE JR., 2004).

Olhar para uma imagem é a primeira leitura que se faz e através dela a leitura de todos os outros códigos serão facilitados, especialmente num mundo onde a imagem tem ganhado predominância em relação a outras formas de comunicação. Entretanto, esse olhar precisa ser aprendido e/ou aperfeiçoado. Saber ler uma imagem pode ampliar a experiência do leitor transformando-o, trazendo novas sensações e desvendando novos horizontes. Oliveira diz que "o primeiro elo que desperta nosso olhar e transfere a ilustração para nossa memória é um sentimento vago, impreciso, que podemos chamar de encantamento, uma qualidade que tem a imagem de nos apaziguar, mesmo que nos inquiete". (OLIVEIRA, 2008, p.36). Essa é uma questão tão

\footnotetext{
${ }^{1}$ Um texto literário é uma construção textual de acordo com as normas da literatura, com objetivos e características próprias, como linguagem elaborada de forma a causar emoções no leitor.
} 
importante que, sem saber ler a imagem, sem o letramento visual o sujeito fica como que à deriva, levado pelos ventos poderosos do conhecimento alheio, sujeito às vontades e determinações que não Ihe são próprias ou que lhe são impostas.

Em princípio as imagens eram feitas para ilustrar o livro e por isso o termo "ilustração". Contudo, eram repetições do texto: ilustrar era mostrar visualmente o que o texto já dizia. Com o passar do tempo isso foi mudando, de repetições e "legendas" do texto, a imagem ganhou um espaço privilegiado, passando a ser produzida como complementação e não apenas "pano de fundo" ou "ornamento" do texto. Isso se deu especialmente nos últimos $100 \operatorname{anos}^{2}$ com o auxílio da tecnologia que se apoderou do uso da imagem. Portanto, fica claro que a imagem literária é fundamental na produção do livro infantil, e que seja qual for a técnica usada deve narrar a história juntamente com o texto verbal. E se não houver um texto verbal, ela deve sustentar a narrativa, trazendo um sentido lógico e cronológico à história para que seja inteligível.

\subsubsection{Breve histórico da literatura infantil}

A literatura infantil surgiu concomitantemente com o conceito de criança e infância. Até o século XVII a criança como um ser em formação era inexistente, e não tinha necessidades específicas. "Sabe-se que, até este século, as crianças não eram percebidas socialmente como seres diferentes dos adultos, compartilhavam o mesmo tipo de roupa, ambientes caseiros e sociais como também o trabalho." (SILVA, 2009, p.134). A concepção de uma faixa etária vista e entendida de forma diferente, com interesses próprios e com necessidade de uma formação específica, só acontece em meados da Idade Moderna e esta mudança se deu por outro acontecimento da época: "a emergência de uma nova noção de família, centrada não mais em amplas relações de parentesco, mas num núcleo unicelular, preocupado em manter sua privacidade (impedindo a intervenção dos parentes em seus negócios internos) e estimular o afeto entre seus membros". (ZILBERMAN, 1985 apud SILVA, 2009, p.136).

A partir do século XVIII a criança começa a ser considerada como tal, e a partir daí a literatura infantil tem seu início. Os contos eram passados de adultos para adultos nas manufaturas e cortes: as crianças presentes também ouviam, e deram o "pontapé" inicial à literatura infantil. As primeiras coletâneas que se perpetuaram foram feitas pelos franceses Jean de La Fontaine (1621-1695) e Charles Perrault (16281703). Os contos frequentavam o imaginário popular há tempos, e é impossível se determinar onde e como surgiram, pois pertenciam somente à oralidade. A partir de Perrault referencia-se o início da história da literatura infantil. Ele reuniu os contos das mulheres fiandeiras contadoras de histórias, e que eram chamadas de "mamães gansa", por isso chama a coletânea de Contos de Mamãe Gansa (1697). Em seguida, os irmãos Grimm (1812) resolvem produzir uma coletânea alemã de contos e também recolhem contos, mas por sua crença cristã os irmãos os reescrevem, adaptando-os conforme achavam ser conveniente.

Foi então que as histórias se espalharam pelo mundo e abriram caminho para os escritores infantis precedidos por Hans Christian Andersen. Ele passa a publicar, além dos contos recolhidos, contos autorais como "O Patinho Feio" e a "A pequena

\footnotetext{
${ }^{2}$ De acordo com Oliveira (2009), a transição do século XIX para o século XX é considerada o período de ouro da ilustração.
} 
vendedora de fósforos" com a diferença de inserir a moral na história e não colocá-la no final como os seus antecessores. A literatura infantil ganha terreno e surgem escritores e textos consagrados até hoje, como C. Collodi (As aventuras de Pinóquio), L. Carrol (As aventuras de Alice no país das Maravilhas e Alice através do espelho), C.S. Lewis (As crônicas de Nárnia) e J. Verne (Viagem ao mundo em 80 dias), entre outros.

No Brasil, o início da literatura infantil é contado a partir de Monteiro Lobato, quando ganha notoriedade e passa a ser considerada no país. Antes dele, a expressão literária ainda era fraca e pouco divulgada. Muitos dos livros eram traduções (ou nem isso) de livros importados de Portugal. "A menina do narizinho arrebitado" (1921) é o clássico que se torna o carro-chefe de uma das séries literárias infantil-brasileira mais famosa até hoje: "O sítio do Pica-Pau Amarelo". Com essa obra, Lobato impulsionou o mercado literário infantil brasileiro, até então bem precário. Foi ele quem fez a primeira grande venda para o governo de São Paulo de 30.000 exemplares. Com as vendas subsequentes fez surgir de maneira consistente o mercado editorial brasileiro.

Depois de Lobato houve uma lacuna na produção literária brasileira. Conforme Ana Maria Machado (2014) 3 relata: "Logo que Lobato morreu houve um primeiro momento terra de ninguém, um pouco aterrorizante de quem iria continuar, houve algumas tentativas, nomes muito respeitáveis, mas há um ponto de silêncio, um vácuo durante algum tempo". Entretanto, essa lacuna não durou muito. Logo vieram escritores que foram leitores de Lobato e influenciados por ele, e que têm feito da literatura infantil brasileira um marco: Ziraldo, Lygia Bojunga, Marisa Lajolo, Ana Maria Machado, Ruth Rocha, Maria Clara Machado, Sylvia Orthof, Joel Rufino, Marina Colasanti, João Carlos Marinho, Pedro Bandeira e outros que, para o bem da literatura brasileira, não eram da área da educação e por isso não estavam atrelados ao caráter didático ao qual a literatura infantil desde sua gênese foi submetida, começando com o próprio Lobato, que era formado em Direito. A preocupação desses escritores estava na linguagem do texto, e não no "destinatário da historinha".

Doravante o Brasil vem se desenvolvendo rapidamente e detém 3 Prêmios Hans Christian Andersen ${ }^{4}$ (HCA), 2 na categoria escritor: Lygia Bojunga (1982) ${ }^{5}$ e Ana Maria Machado (2000) e o terceiro, em 2014, na categoria ilustrador, de Roger Mello.

Em entrevista ao programa "Vereda Literária", Bartolomeu Queirós (também indicado ao HCA em 1998 e 2008) comenta o quanto a produção de literatura cresceu no Brasil e como os projetos estão cada vez melhores. Apesar de lamentar a falta de interesse e de público para uma produção mais aprimorada da literatura no que tange ao seu conteúdo, argumenta que publicar um texto bom pode não ser um opção porque ele não irá suportar uma nova edição. (Queirós, 2015). Esse é o outro lado da produção editorial. O "verso da folha" traz em letras bem miúdas quase um contrato com o leitor/consumidor, sem esquecer autores e até editores, impelindo-o a escolhas que nem sempre são próprias ou necessárias. A sedução que o mercado exerce com intuitos puramente lucrativos, fonte também de produções sem conteúdo e baixa

\footnotetext{
${ }^{3}$ Vídeo "Seminário Brasil, brasis: A literatura infantil e juvenil na atualidade", publicado pela Academia Brasileira de Letras.

${ }^{4}$ O HCA é o mais alto reconhecimento internacional a um autor e um ilustrador de livro infantil. Anualmente, a Organização Internacional do livro infantil (IBBY) oferece ao autor e ilustrador cuja obra contribui para a literatura infantil de forma duradoura.

${ }^{5}$ As obras citadas são apenas para referência. O Prêmio HCA é pelo conjunto da obra e não uma obra específica.
} 
qualidade gráfica, é comparada à Odisséia de Ulisses por Castro: "a situação imposta pela indústria editorial quanto à produção, divulgação e circulação do livro produto faz com que o leitor/consumidor embarque numa "odisséia" para garantir sua autonomia na relação travada com a obra". Comparando o mercado aos inimigos de Ulisses, diz que ele prepara ações extremamente sedutoras para conduzir o leitor à "condição única e exclusiva de consumidor, desviando-o de uma trajetória que the possibilite autonomia e autoria no ato de ler". (CASTRO, 2002, p.6,7).

Se a literatura clássica sofre com a mercantilização, o que dizer da literatura infantil? Desde que o mercado descobriu o universo da criança como quem descobre um tesouro, seu foco de interesse e marketing volta-se para ele - afinal, é necessário estimular o consumo desse novo nicho. Inicia-se um movimento mercadológico para criar uma estética de espetáculo no público direcionando o mesmo à sua produção. $A$ rede mercadológica foi construída para "fisgar o peixe". Se de um lado é positiva a influência mercadológica estimulando e colocando o livro na mão do sujeito, por outro, o leitor fica à mercê das "ondas literárias" que mais estão em alta. Para Castro $(2002$, p.4) "O livro literário torna-se, ao mesmo tempo, veículo de massificação - pela forma como é tratado - e possibilidade de superação dessa condição, pelas características inerentes à criação artística".

Apesar da inquietante situação de adequação forçada de escritores e leitores imposta pelo mercado, essa característica própria da literatura, como de todas as artes, a de transcender limites e condições impostos, é que sustenta e fertiliza a produção de bons livros. E, mesmo que lentamente, brasileiros e brasileirinhos vão tendo a chance de acesso a essa chave transformadora: a literatura.

\subsubsection{Breve histórico da imagem literária infantil}

A imagem sempre fez parte da vida humana tanto como expressão quanto como comunicação. "Tratar a imagem como um dos mais significativos veículos de comunicação disponibilizado pelo homem, me parece coerente e inevitável". (HADDAD, 2008, p. 19). A imagem foi sendo cada vez mais utilizada, dos artefatos às narrativas. Como ilustração nos livros infantis, ela surge com a mesma ideia do próprio livro, tendo uma função didática, como em "Orbis sensualium pictus" (1658) com a técnica xilogravura, que compunha texto e imagem com maior versatilidade (LINDEN, 2011, p.11). Contudo, as técnicas foram evoluindo até a criação da prensa, que foi um grande passo para a produção em massa do livro em que havia texto e imagem. A inovação de Gutenberg modificou a história do conhecimento no mundo. Na mesma época da Revolução Industrial (1830 aproximadamente) os clássicos infantis eram ilustrados na França como os contos de Perrault, Sophie - Condessa de Ségur e JeanneMarie Leprince de Beaumont e na Alemanha, os contos dos irmãos Grimm. Para Oliveira (2009, p.14) é nas imagens de Perrault (1695), irmãos Valentin \& Orson (1489) que se encontram os "alfarrábios ${ }^{6}$ da história da ilustração" nos quais convenções visuais se perpetuaram tanto em termos gráficos como no imaginário popular.

Após a Segunda Guerra Mundial o livro infantil fica relegado à segundo plano, em parte pela morte de grandes ilustradores, em parte pela lei da censura do Brasil de 1949 proibindo imagens de violência e racismo (Linden, 2011). Ainda assim o livro infantil persiste, e o editor Robert Delpire contribui significativamente para o avanço

${ }^{6}$ Alfarrábio significa livro antigo ou velho, e de pouco préstimo, ou valioso por ser antigo. (Ferreira, 1985) 
da imagem no livro ilustrado nos anos de 1950-60, que trabalhava não só com o conteúdo do livro, mas com sua materialidade, pensando em todos os seus componentes. A partir daí o livro ilustrado só ganhou espaço com novos autores, ilustradores e editores, prova incontestável do poder da imagem em comunicar. Para Linden (2011, p.21) "parece que a imagem se afirmou a ponto de "contaminar" o conjunto das mensagens e fazer do livro ilustrado um objeto visual a priori".

Graça Lima (2009) comenta que inicialmente no Brasil a imagem está muito vinculada às revistas, já que os primeiros livros brasileiros eram em preto e branco importados da França e Portugal. É Lobato quem percebe que o Brasil precisa de um parque gráfico. A ideia de que brasilidade e modernidade deveriam andar juntas gerou - Movimento Modernista, momento em aproveitou para montar a primeira empresa com equipamentos próprios à produção de livros. Nos anos 50 o país dá um salto em termos de industrialização. A hegemonia cultural francesa se torna obsoleta e a admiração pelo estilo americano cresce: a criação gráfica é atingida pela visão americana. JK reequipa a indústria gráfica, que cresce espantosamente nessa década.

Apesar da censura imposta pelo governo militar, há incentivo à produção, com investimento em infraestrutura para a indústria, subsídios, diminuição de impostos e taxas de importação. Nos anos 70 a produção cresce e o projeto gráfico passa a ser incorporado nas novas tendências de mercado. A Editora Ática passa a oferecer às crianças obras com propostas gráficas inovadoras como não se havia visto ainda. São destaques dessa época Eliardo França com a coleção "Gato e Rato", Ziraldo com "Flicts" e Gian Calvi com "O menino Mágico" de Raquel de Queiroz. Segundo Spengler (s.d.), Flicts, de 1969, foi o marco de uma inovação que abriu as portas para o livro ilustrado: imagem e texto intimamente ligados, a complementação de ambos é que faz a narrativa do livro de Ziraldo.

A década de 80 traz nomes como Rui de Oliveira, Juarez Machado, Eva Furnari, Angela Lago, Jô de Oliveira, Ricardo Azevedo, Regina Yolanda, Walter Ono, Ciça Fitipaldi, Claudio Martins, Miadara, Alcy e Michelle. A literatura infantil entrou em foco, e os leitores foram contemplados com textos adequados ao seu nível de compreensão com excelente qualidade visual. Na década de 90 surge uma geração de ilustradores designers que assumem a elaboração do projeto gráfico e aliados às novas tecnologias de produção, possibilitam um alto nível de qualidade do livro infantil. Para Lima, ainda é pequena a oferta de cursos de formação específica para ilustradores, mas "a criação vertiginosa dos cursos de design implementou o crescimento de mãode-obra na área. André Neves, Andrés Sandoval, Cristina Biazeto, Fernando Vilela, Salmo Dansa, Suppa, Rosinha Campos, Ana Terra marcam este novo panorama gráfico e que ainda vai fazer surgir muitos novos talentos". (LIMA, 2009, p.33).

\subsubsection{O público infantil}

Quando se pensa em classificação, surge a ideia de separação por níveis, filtragem, seleção. Entretanto, ela é tomada apenas como direcionamento, necessário para a aplicação do livro e a tomada de resultados. Hoje os estudos já avançaram e ainda não há uma base totalmente definida para uma "classificação segura". Cada livro pode oferecer leituras diferentes para pessoas da mesma faixa etária, sua experiência e conhecimento adquirido, que irão influir nessa leitura, podendo o leitor ir mais além ou não na leitura que fará. "A evolução nos estágios de leitura de imagens tem pouco a ver com a idade cronológica e sim com as experiências de leitura de cada leitor; está 
relacionada à frequência com se relaciona com a imagem, com o seu meio cultural e se há uma mediação que provoque leituras cada vez mais aprofundadas". (CARNEIRO E MANINI, 2009, apud ALBUQUERQUE et al, 2014).

Neste estudo, a fase abordada está entre o estágio operatório concreto, com crianças de 7 e 8 anos de uma escola estadual, e não havendo nenhum tipo de interferência ou auxílio dos professores a não ser pela indicação de quais crianças participariam da amostra. Nesta fase a criança já começa a abstrair, com um maior domínio da linguagem, seu raciocínio está mais estruturado e compreende noções de espaço, tempo, velocidade, ordem e outros. A imaginação e a fantasia ainda estão bem ativas, entretanto ela já começa a diferenciar fantasia de realidade. Também já são capazes de representar, o que permite que criem suas próprias histórias e narrativas, por exemplo, ao ler as imagens de um livro, ou até recontar a história lida, modificando-a. Uma predominância do texto visual sobre o texto verbal pode oportunizar uma leitura mais aberta da obra, portanto, uma gama maior de leituras e percepções - o que é relevante para este estudo.

\section{METODOLOGIA}

Esta pesquisa é de natureza exploratória, descritiva, qualitativa e aplicada, baseada em Lakatos e Marconi (1991), Gil (2002) e Milles e Huberman (1994). O delineamento é feito de dados primários (pesquisa bibliográfica), cujo objetivo foi embasar a análise do experimento feito com as crianças e o livro; e de dados secundários (documental) na qual foi realizada uma análise de similares com três livros da literatura infantil selecionados pela qualidade do projeto gráfico, imagem e texto: "A grande viagem da senhorita Prudência" de Charlote Gastaut; "Calma, Camaleão" de Laurent Cardon e "Tatu-Balão" de Sônia Barros e Simone Matias. As unidades de análise foram: paleta de cores, ilustração, tipografia, diagramação e tamanho. 0 resultado da análise pode ser visto no quadro 1.

Quadro 1-Resultados da análise de similares

\begin{tabular}{|c|c|c|c|c|}
\hline $\begin{array}{l}\text { Unidade de } \\
\text { análise }\end{array}$ & Variáveis & $\begin{array}{l}\text { Similar } 1 \\
\text { Calma, camaleão }\end{array}$ & $\begin{array}{l}\text { Similar } 2 \\
\text { Prudência }\end{array}$ & $\begin{array}{l}\text { Similar } 3 \\
\text { Tatu-Balão }\end{array}$ \\
\hline $\begin{array}{l}\text { Paleta de } \\
\text { cores }\end{array}$ & $\begin{array}{l}\text { Complementares } \\
\text { Análogas } \\
\text { Triádicas } \\
\text { Monocromáticas }\end{array}$ & $\begin{array}{l}\text { Predominância } \\
\text { Triádica } \\
\text { Tons fortes e } \\
\text { vibrantes, grande } \\
\text { variação de tons }\end{array}$ & $\begin{array}{l}\text { Predominância } \\
\text { Triádica } \\
\text { Tons fortes com } \\
\text { grande variação de } \\
\text { tons e cores }\end{array}$ & $\begin{array}{l}\text { Predominância de } \\
\text { Análogas sobre o } \\
\text { fundo branco ou } \\
\text { marrom. }\end{array}$ \\
\hline Ilustração & $\begin{array}{l}\text { Manual } \\
\text { Digital } \\
\text { Mista }\end{array}$ & $\begin{array}{l}\text { Manual, personagens } \\
\text { com contorno em } \\
\text { preto e muito } \\
\text { expressivos }\end{array}$ & $\begin{array}{l}\text { Manual, } \\
\text { Cores muito vivas, } \\
\text { sem contorno }\end{array}$ & $\begin{array}{l}\text { Manual, } \\
\text { Sem contorno, } \\
\text { pintura em tinta } \\
\text { (guache ou acrílica) }\end{array}$ \\
\hline Tipografia & $\begin{array}{l}\text { Serifada } \\
\text { Sem serifa } \\
\text { Manuscrita }\end{array}$ & Sem texto & Manuscrita & Manuscrita \\
\hline Diagramação & $\begin{array}{l}\text { Ilustração } \\
\text { Texto }\end{array}$ & $\begin{array}{l}\text { Somente ilustração } \\
\text { sem texto escrito }\end{array}$ & $\begin{array}{l}\text { Texto se relaciona } \\
\text { com a forma da } \\
\text { ilustração }\end{array}$ & $\begin{array}{l}\text { Texto dentro da } \\
\text { área da ilustração }\end{array}$ \\
\hline Tamanho & $\begin{array}{l}\text { Grande } \\
\text { Médio } \\
\text { Pequeno }\end{array}$ & $\begin{array}{l}\text { Médio - medida: } \\
27,5 \times 17,5 \mathrm{~cm}\end{array}$ & $\begin{array}{l}\text { Grande- medida: } \\
33,5 \times 25,7 \mathrm{~cm}\end{array}$ & $\begin{array}{l}\text { Médio- medida: } \\
27,5 \times 19 \mathrm{~cm}\end{array}$ \\
\hline
\end{tabular}

Fonte: Elaborado pelo autor, com base na pesquisa realizada. 
A Estratégia foi a videofotoetnografia, em duas etapas: a primeira realizada na pré-produção do livro, com o intuito de fazer a criança participar do processo de produção de imagem e projeto gráfico. Foram criados cards de opções de imagem com estilos diferentes de pintura em aquarela e traço; tipografia com fontes manuscristas e impressas em caixa alta e baixa; texturas em cards de papel vegetal $90 \mathrm{~g}$ e offset $120 \mathrm{~g}$ e $300 \mathrm{~g}$ e, para formatos, sulfite representando os tamanhos $33,5 \times 25,7 \mathrm{~cm}, 21 \times 29,7$ $\mathrm{cm}, 27,5 \times 19 \mathrm{~cm}, 27,5 \times 17,5 \mathrm{~cm}$ e $18 \times 12,5$. Para cada opção elas escolheram o que mais Ihes agradava. O livro foi produzido com base nos resultados obtidos. Com o livro pronto, realizou-se a segunda etapa, com a leitura por crianças de 7 e 8 anos, de escolas públicas e particulares no estado de Minas Gerais. Foi realizada no período de férias, por isso as crianças foram filmadas e fotografadas em ambientes fora da escola. O propósito foi validar as imagens e o texto criados. Cada criança leu o livro e posteriormente houve uma conversa sobre suas percepções do livro em relação às imagens, à narrativa textual, o que chamou mais atenção e o que ela mudaria. As leituras foram gravadas em vídeo e fotografadas para posterior observação e análise das reações e das conversas e com os dados coletados houve o refinamento do texto, das imagens e do projeto gráfico do livro.

As duas etapas foram essenciais para que o livro fosse produzido sob uma ótica infantil e não apenas do autor do texto, além de auxiliar tanto na produção quanto no refinamento do projeto, pois a primeira etapa possibilitou a direção da produção do livro e a segunda etapa apontou acertos e erros da produção que puderam ser ajustados antes da produção final, permitindo assim uma margem muito maior de aceitação pelo público alvo.

A metodologia de projeto aplicada para a construção do livro foi baseada no processo de design thinking, que segundo Demarchi, Fornasier e Martins (2010), a partir da classificação de Brown (2010), compreende: observação, compreensão, criação, protótipo e internalização, sem a qual não há a compreensão do projeto em toda a sua complexidade, ou seja, não há aprendizado. O Delineamento de dados para a fundamentação do processo de produção do livro e da imagem, assim como a análise de similares, estudo de público e mercado compreendem as etapas observação e compreensão. O Delineamento do projeto gráfico, a criação; a produção do livro, a prototipagem. A internalização é a pesquisa com as crianças, que indicaram a compreensão dos objetivos do livro. O projeto também se baseou no Design thinking for educators, da IDEO (2012) cujas etapas são: descoberta (inspirar-se e criar novas ideias, entender o desafio); interpretação (transformar histórias em insights); ideação (geração de várias ideias); experimentação (dar vida a elas); prototipação (torna-las tangíveis, aprender enquanto as constrói e dividi-las com outras pessoas); e evolução (desenvolver o conceito no tempo). Adequando as fases têm-se: Descoberta: a criança percebe o livro e vai descobrindo a história à medida que lê; Interpretação: compreende a narrativa e absorve a história lida; Ideação: passa a ter uma ideia e imaginar. Cria a partir do que interpretou, imageticamente, em relação ao texto e à imagem. Emoção gerada pela narrativa; Experimentação: momento de interação numa forma mais concreta. Experimenta os elementos sugeridos ou busca informações comentadas na narrativa; e Evolução: partirá de suas proposições criadas pós-leitura e experimentação. Essa fase dependerá de quanto se sentiu estimulada e impactada pela narrativa e experimentos. Sensações e emoções geradas. 


\section{PROPOSTA DO LIVRO}

\subsection{Apresentação}

O livro não tem a função de ensino, mas de fruição da leitura. Um ponto importante é a relação imagem e texto, a interação e ancoragem entre ambos e a participação da criança, tanto na leitura quanto no processo de produção do livro. 0 tema central chuva, autoral, remete à infância e relações emocionais que originou a história. A autora é também ilustradora e designer gráfica e desenvolveu tanto texto escrito, imagético e o projeto gráfico concomitantemente. Sendo a chuva o tema central o conceito empregado foi o da sensação de água, molhado, respingado, razão pela qual se empregou a técnica aquarela. As páginas são compostas de acordo com o texto, complementando-o. O livro possui $29,7 \times 21 \mathrm{~cm}, 36$ páginas, lombada quadrada, costurado e colado. As ilustrações (figura 2) com efeito "aguado": ora chuviscado, manchado, com um efeito mais líquido, mais ou menos saturado, mais ou menos definido e estilo de traço apontado pelas crianças. O projeto inclui materiais diferentes como papel vegetal $90 \mathrm{~g}$ e offset em gramaturas diferentes, $120 \mathrm{~g}$ e $300 \mathrm{~g}$, para proporcionar a ideia da chuva que aumenta aos poucos.
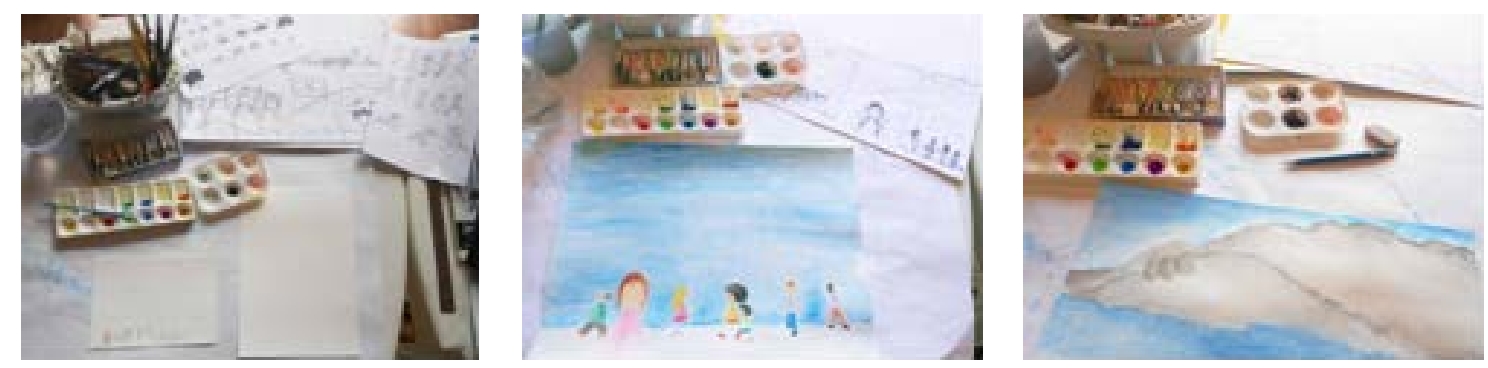

Figura 2 - Processo de criação e pintura de ilustrações

Fonte: Elaborado pelo autor, com base na pesquisa realizada.

A transparência do papel vegetal reforça a ideia de leveza da chuvinha por sua transparência. O offset entra no momento em que a chuva se torna mais densa e sua gramatura aumenta conforme a chuva aumenta, tornando a narrativa mais dramática e trazendo uma experiência sensorial. A figura 3 mostra a página dupla, trecho em que a chuvinha é ajudada por seus amigos tempestade, raio e trovão e a figura 4, as páginas pós-textuais com atividades para dias de chuva. A ideia é prorrogar a leitura para além da narrativa e do livro e ao mesmo tempo estimular o retorno ao texto. As folhas pós-textuais (figura 4) sugerem o que fazer em dia de chuva e atividades relacionadas às cores do arco íris formadas pelo prisma e a intenção é induzir o leitor a voltar ao texto para conferir detalhes e descobrir elementos que na leitura possam ter passado despercebidos (ou se percebidos, para conferência). Isso faz com que a interação com o livro continue mesmo após a leitura. As experiências sugeridas tornam a leitura prolongada, gerando o ciclo proposto no processo de design thinking. Assim, a proposta é bem traduzida por Alarcão (s.d.): “... o trabalho do ilustrador nasce, e existe dentro do universo do designer. Nossas ilustrações existem no contexto da linguagem do design, suas estratégias criativas, a influência do cliente e claro, as páginas ou suportes cujo conteúdo é território do designer." 


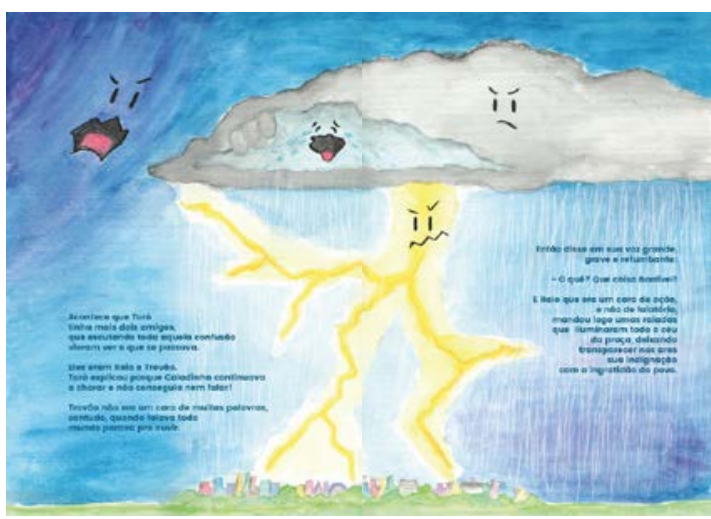

Figura 3 - Tempestade

Fonte: Elaborado pela autora, com base na pesquisa realizada.

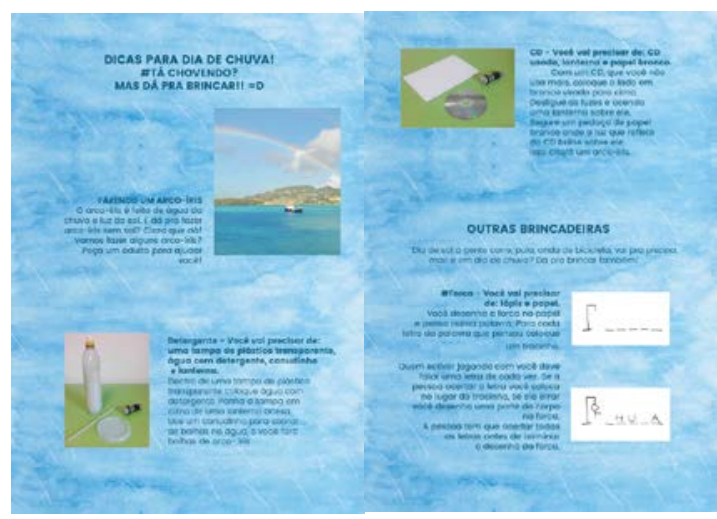

Figura 4 - Dicas e atividades

Fonte: Elaborado pela autora, com base na Pesquisa realizada.

\section{CONCLUSÃO}

Os caminhos da produção de imagem são muitos e podem ser tortuosos (por vezes até perigosos). Contudo, é possível percorrê-lo com atenção, cuidado e sensibilidade que o público infantil exige. Foi possível verificar que a produção da imagem literária é bem diferente da didática, que carrega a função de explicitar, educar e instruir. Já no livro literário a imagem não está imbuída dessa função e tem muito mais uma relação de complementariedade. Assim, o cuidado para não representar o que já foi escrito deve ser redobrado. Toda a produção deve ser cuidadosamente pensada, dos ângulos ao traço, dos materiais às cores para que essa interação com o texto escrito seja a maior possível.

No livro produzido houve intensa interação das crianças com a imagem. Elas buscaram compreendê-las e mostraram curiosidade no desenrolar da história, expressando de forma clara as reações ao passar das páginas. Primeiro compreendiam a cena, e depois passavam à leitura do texto propriamente dita. Apesar da predominância do azul e do cinza, o livro ficou bem colorido, o que chamou muito a atenção das crianças, que reagiam positivamente para as páginas mais coloridas, dando preferência a elas; torcida para os personagens e reações emocionais às cenas. A compreensão total da história se deu em $98 \%$ das crianças. Uma delas identificou a diferença de tipografia e relatou que deveria ser igual em todas as páginas. A diagramação e o projeto gráfico foram fundamentais para a compreensão e interação das crianças com o texto e a história comprovando que é de extrema importância que o projeto gráfico seja bem pensado e trabalhado e que ele pode estimular ou desestimular a interação da criança com o texto e as imagens.

A pesquisa de validação foi imprescindível para a finalização do livro. Através dela foi possível detectar erros e acertos, dificuldades e percepções a fim de melhorar o projeto gráfico. A produção do livro foi bem sucedida no que se refere à verificação da importância da imagem literária, sua relação com o texto e com o projeto gráfico. Apesar de não ser conclusiva por ter sido testado por poucas crianças, a pesquisa mostra indicativos de eficiência e eficácia, contribuindo para reflexões, desenvolvimento de outras pesquisas e discussões especialmente em relação à imagem literária e o projeto gráfico. 


\section{REFERÊNCIAS}

ALBUQUERQUE; T. C., COSTA, J.S.; CARNEIRO-LEÃO, Ana Maria A. As possibilidades de leitura de imagens para a formação de professores. Alagoas: UFRPE, 2014.

BROWN, Tim. Design Thinking - uma ponderosa ferramenta para decretar o fim das velhas ideias. Rio de janeiro: Elsevier, 2010.

CASTRO, M. G. M. A indústria e a produção do livro infantil. Universidade Estadual de Goiás. Anápolis, 2002.

DEMARCHI, A.P.; FORNASIER, C.B.R.; MARTINS, R.F.F. Design thinking no processo de gestão de design: um estudo de caso na agricultura familiar. In Anais $9^{\circ}$ Congresso Brasileiro de Pesquisa e Desenvolvimento em Design. São Paulo, Brasil: outubro, 2010.

DUARTE JUNIOR, F.. O sentido dos sentidos. Curitiba: Criar, 2004.

FIPE. Fundação Instituto de Pesquisas Econômicas, 2014.

GIL, A. C.. Como elaborar projetos de pesquisa. 4 ed. São Paulo: Atlas, 2002.

HADDAD, L. A ilustração literária. Londrina: Ilustres Ideias, 2008.

IDEO. Toolkit: Design Thinking for Educators, 2012. Disponível em:

<http://www.designthinkingforeducators.com/DTtoolkit_v1_062711.pdf> Acesso em:

20 nov. 2015. Disponível em: <http://www.isbn.bn.br/website/o-que-e-isbn> Acesso em ago. 2015.

LAKATOS, E. M.; MARCONI, M.A. Fundamentos de metodologia científica. 3. ed. São Paulo: Atlas 1991.

LIMA, G. A arte de ilustrar livros para crianças e jovens. Salto para o futuro. Secretaria de Educação à Distância. Ano XIX -no 7 - junho/2009.

LINDEN, S. V. Para ler o livro ilustrado. São Paulo: Cosac Naify, 2011.

MACHADO, A.M. Seminário Brasil, brasis: a literatura infantil. Academia Brasileira de Letras. (03/09/2014). Disponível em:

<https://www.youtube.com/watch?v=TcAdOFZwx4g> Acesso em: 2015.

MILES, MB.; HUBERMAN, AM. Qualitative Data Analysis. CA: Sage Publications, Thousand Oaks, 1994.

OLIVEIRA, R. Pelos Jardins Boboli: reflexões sobre a arte de ilustrar livros para crianças e jovens. Rio de Janeiro: Nova Fronteira, 2008.

. A arte de ilustrar livros para crianças e jovens. Salto para o futuro. Secretaria de Educação à Distância. Ano XIX -no 7 - junho/2009.

QUEIRÓS, BARTOLOMEU CAMPOS. Programa VEREDA LITERÁRIA: (24/05/2002)

Disponível em: <https://www.youtube.com/watch?v=zHNwnTDtNgg> Acesso em: set 2015.

SILVA, A. L. Trajetória da literatura infantil: da origem histórico e do conceito mercadológico ao caráter pedagógico na atualidade. Revista Eletrônica de Educação do UNIVEM, Marília, v.2-n.2, p.135-149, 2009.

SPLENGER, M. L. P. Literatura infantil: a palavra e a imagem se entrelaçando na história. Leitura: Teoria e Prática, v. 29, n. 56, UNISUL, Santa Catarina. 2011. Disponível 
em: <http://revista.univem.edu.br/index.php/REGRAD/article/view/234/239> Acesso em: 03 ago 2015. 